\title{
Parentalidade (In)Desejada: Avós e Tias que Cuidam dos Filhos(as) de Mulheres Presas
}

Parentalidad (In)Deseada: Abuelos y Tías que Cuidan a los Hijos de las Mujeres Presas

Parenting (In)Desired: Grandparents and Aunts who Care for the Children of Prey Women

\author{
Liziane Falleiro dos Santos Arruda \\ ORCID: http://orcid.org/0000-0002-1007-034X \\ Universidade Franciscana, Rio Grande do Sul/Brasil
}

Luciane Najar Smeha

ORCID: http://orcid.org/0000-0002-3068-3776 Universidade Franciscana, Rio Grande do Sul/Brasil

Declaração de Direito Autoral

A submissão de originais para este periódico implica na transferência, pelos autores, dos direitos de publicação impressa e digital. Os direitos autorais para os artigos publicados são do autor, com direitos do periódico sobre a primeira publicação. Os autores somente poderão utilizar os mesmos resultados em outras publicações indicando claramente este periódico como o meio da publicação original. Em virtude de sermos um periódico de acesso aberto, permite-se o uso gratuito dos artigos em aplicações educacionais e científicas desde que citada a fonte conforme a licença CC-BY da Creative Commons.

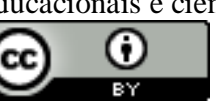

Creative Commons Atribuição 4.0 Internacional.

\section{Resumo}

Objetivou-se conhecer a experiência da parentalidade exercida por mulheres que, diante da prisão de suas filhas, noras ou irmãs, assumiram a responsabilidade de crianças e/ou adolescentes que foram privados dos cuidados exercidos pela mãe biológica. Trata-se de uma pesquisa qualitativa, na qual participaram cinco avós e duas tias maternas. Foi realizada uma entrevista semiestruturada com questões sobre a rotina de cuidados com a criança/adolescente. A produção dos dados ocorreu em uma cidade do interior do estado do Rio Grande do Sul, no período entre Abril e Agosto de 2018. Os dados foram transcritos e submetidos à análise de conteúdo de Bardin. Concluiu-se que as participantes, mesmo diante de dificuldades como situação financeira restrita, pouca escolaridade, falta de apoio social e problemas oriundos da própria faixa etária, assumiram a responsabilidade de cuidar das crianças/adolescentes. O cenário desta rotina é árduo e permeado por sentimentos ambivalentes em relação à presa, contribuindo para que elas não invistam na manutenção do vínculo mãe-filho(a). A maioria das cuidadoras participantes deseja devolver os menores as suas mães, quando finalizado o cumprimento da pena.

Palavras-chave: Mães presas; Cuidadoras; Relação familiar; Parentalidade.

\section{Resumen}

Se objetivó conocer la experiencia de la parentalidad ejercida por mujeres que, ante la prisión de sus hijas, noras o hermanas, asumieron la responsabilidad de niños y / o adolescentes que fueron privados de los cuidados ejercidos por la madre biológica. Se trata de una investigación cualitativa, en la que participaron cinco abuelos y duas tías maternas. Se realizó una entrevista semiestructurada con preguntas sobre la rutina de cuidados con el niño / adolescente. La producción de los datos ocurrió en una ciudad del interior del estado de Rio Grande do Sul, en el período entre abril y agosto de 2018. Los datos fueron transcritos y sometidos al análisis de contenido de Bardin. Se concluyó que las participantes, incluso ante dificultades como situación financiera restringida, poca escolaridad, falta de apoyo social y problemas oriundos de la propia franja etaria, asumieron la 
responsabilidad de cuidar de los niños / adolescentes. El escenario de esta rutina es arduo y permeado por sentimientos ambivalentes en relación a la presa, contribuyendo para que ellas no inviertan en el mantenimiento del vínculo madre-hijo (a). La mayoría de las cuidadoras participantes desea devolver a los menores a sus madres, cuando finalizado el cumplimiento de la pena.

Palabras clave: Madres presas; Cuidadoras; Relación familiar; Parentalidad.

\begin{abstract}
The objective of this study was to know about the experience of parenting exercised by women who, in the face of the arrest of their daughters, daughters-in-law and sisters, assumed responsibility for children and / or adolescents who were deprived of the care exercised by biological mothers. This is a qualitative research, in which 5 grandmothers and 2 aunts participated. A semi-structured interview was conducted with questions about the child / adolescent care routine. The data were produced in a city in the interior of the state of Rio Grande do Sul, between April and August 2018. The data were transcribed and submitted to the thematic content analysis of Bardin. It was concluded that the participants, even the financial and social difficulties, did not give up the responsibilities involved in caring for their grandchildren and nephews. They have fully assumed parental functions, overloading their daily routines in some way.
\end{abstract}

Keywords: Mothers prisoners; Caretakers; Family relationship; Parenting.

\section{Introdução}

Este artigo versa sobre a experiência de cuidado na vida de mulheres que, diante da prisão de suas filhas, noras ou irmãs, assumiram a criação de crianças/adolescentes, filhos(as) biológicos dessas mães presas no sistema carcerário. $\mathrm{Na}$ realidade da prisão materna, o rompimento dos laços afetivos e sociais são inevitáveis, obrigando as mães a abdicarem de suas funções de mantenedoras do lar e de responsáveis pela educação de seus(suas) filhos(as), para entregá-los(as) a outros cuidadores, geralmente pessoas da família. O que repercute no empobrecimento da relação dessas mulheres com seus(suas) filhos(as) (Diuana, Ventura, Simas, Larouzé, \& Correa, 2016). O Brasil possui a quinta maior população de mulheres encarceradas do mundo, sendo que $50 \%$ delas têm entre 18 e 29 anos, e 74\% são mães, quase todas eram as principais responsáveis pelos cuidados e criação dos(as) filhos(as) até o momento da prisão (Brasil, 2017).

Por meio da revisão de literatura estabelecida para esta pesquisa, foi possível verificar uma escassez de estudos brasileiros sobre o contexto prisional feminino e as questões que envolvem essa população, como: a gestação e a maternidade vivenciadas num contexto de extrema vulnerabilidade social; a manutenção do vínculo com os(as) filhos(as) após a detenção, sendo crianças ou adolescentes. Sobre as redes de apoio familiar dessa população, os estudos são quase inexistentes, ratificando a invisibilidade dessas famílias na sociedade.

As mães presas são triplamente condenas. Primeiro pela prisão, posteriormente pela perda da vinculação e convivência com seus(suas) filhos(as), seguido pelo abandono por parte de seus familiares. Não é raro observar que, durante o cumprimento de sua pena, a mãe presa perca as referências familiares, pois seus(suas) filhos(as) passam a ser cuidados por outras mulheres, que por vezes podem dificultar a elaboração e manutenção dos elos maternos até então constituídos com os(as) filhos(as) (Lopes, 2015).

Conforme a cartilha da mulher presa no Brasil, a mãe não perde a guarda de seu(sua) filho(a), a não ser em caso de crime doloso contra o(a) mesmo(a). A guarda apenas é suspensa até o julgamento definitivo, ou então, 
se a mãe for condenada por sentença da qual não caiba mais recurso e cuja pena seja superior a dois anos de prisão. Sendo assim, a guarda do(a) filho(a) menor caberá ao marido, parentes ou amigos da família. Com a conclusão da pena, e não havendo decisão judicial contrária, a mãe volta a ter a guarda e o poder familiar que haviam sido suspensos em razão da condenação (Brasil, 2012a).

Visando a manutenção dos laços e a convivência, a Lei $\mathrm{n}^{\circ} 12.962$, de 8 de abril de 2014, garantiu a crianças e adolescentes o direito à convivência com pais privados de liberdade, assegurando a participação dos mesmos no processo de desenvolvimento de seus(suas) filhos(as), ainda que afastados do lar. No entanto, a lei mencionada deixou de definir qual órgão seria responsável por atribuir a tarefa de viabilizar esse contato (Brasil, 2014).

No que refere ao direito à convivência familiar e ao exercício da parental, Figueiredo e Lamela (2014), definem a parentalidade como uma dimensão estável que corresponde ao ambiente físico e emocional oportunizado pelos cuidadores na prática, onde o estilo parental exercido influencia diretamente nas atividades diárias e psicológicas de uma criança. Sendo vista também como prática, a parentalidade é aquilo que ocorre cotidianamente durante as práticas educativas e que são influenciadas por valores e crenças que, por sua vez, são construídas pela cultura e história (Piccinini \& Alvarenga, 2012).

As mulheres assumem com mais frequência do que os homens os encargos da parentalidade provisória; enquanto que os homens apresentam maior facilidade de se afastarem da família e dos cuidados parentais. Essa função do cuidar está estreitamente relacionada à vivência da maternidade, pois a mesma empodera técnicas de preservação da vida e da espécie, independente do contexto no qual estão inseridas (Lopes, 2015).

Sendo assim, em especial as avós, acabam por desempenhar a função de mães substitutas, pois dificilmente se recusam a assumir essa responsabilidade, uma vez que se sentem comprometidas também com a descendência de darem educação e cuidados aos(as) filhos(as) de seus(suas) filhos(as), mesmo que lhe causem prejuízos pessoais, físicos e financeiros (Oliveira, 2011). Ainda que muitas delas desejem apenas auxiliar nas atividades diárias, outras realizam essa função da criação e educação de uma forma imposta, em decorrência do comportamento de seus(suas) filhos(as), como referido nessa pesquisa, em que as avós não optaram voluntariamente por criar os netos (Cardoso \& Brito, 2014).

No caso deste estudo, as mulheres avós/tias não escolheram ou desejaram assumir a responsabilidade iminente, mas assim fizeram por não haver outra pessoa disponível a ficar com os(as) menores. Isso significaria não suscitar um novo abandono na vida de quem já sofre pela separação materna. Este artigo objetivou conhecer a experiência de parentalidade exercida por mulheres que, diante da prisão de suas filhas, noras ou irmãs, assumiram a responsabilidade de crianças e/ou adolescentes que foram privados dos cuidados exercidos pela mãe biológica.

\section{Método}

Trata-se de uma pesquisa qualitativa realizada em uma cidade do interior do estado do Rio Grande do Sul, no período entre abril e agosto de 2018. As participantes da pesquisa foram 7 mulheres, sendo 5 avós (4 avós maternas e 1 avó paterna) com idades que variam de 55 a 68 anos, e 2 tias maternas com idades entre 26 e 33 anos, que assumiram os cuidados dos menores após a prisão de suas mães. Quanto ao estado civil dessas mulheres, 3 são casadas, 2 divorciadas, 1 viúva e 1 solteira. No quesito escolaridade, a maioria possui o Ensino Fundamental Incompleto, tendo 1 sem alfabetização e 1 com Ensino Médio Incompleto. Em relação às atividades laborais, todas, no momento da entrevista, exerciam somente atividades domésticas.

Para preservar a identidade das participantes neste estudo, elas foram nomeadas por meio da letra $\mathrm{C}$, inicial da 
palavra cuidadora seguida de um número arábico, conforme a ordem na qual as entrevistas foram realizadas. Com vistas a

Tabela 1

Caracterização das cuidadoras participantes melhor caracterizar as participantes, os dados da entrevista sociodemográficos foram organizados na Tabela 1.

\begin{tabular}{|c|c|c|c|c|c|c|c|}
\hline Cuidadora & Idade & Escolaridade & Profissão & $\begin{array}{l}\text { Menores } \\
\text { que cuida/ } \\
\text { filhos de } \\
\text { mãe presa }\end{array}$ & $\begin{array}{l}\text { Número de } \\
\text { fillhos } \\
\text { biológicos }\end{array}$ & $\begin{array}{c}\text { Estado } \\
\text { Civil }\end{array}$ & $\begin{array}{c}\text { Grau de } \\
\text { Parentesco } \\
\text { c/ a presa }\end{array}$ \\
\hline $\mathrm{C} 1$ & 65 & Analfabeta & Do lar & 2 netos & 8 & Viúva & Mãe \\
\hline $\mathrm{C} 2$ & 58 & $\begin{array}{c}\text { Não } \\
\text { informado }\end{array}$ & Do lar & 1 neto & 4 & Divorciada & Mãe \\
\hline $\mathrm{C} 3$ & 62 & $\begin{array}{c}\text { Ensino } \\
\text { fundamental } \\
\text { incompleto }\end{array}$ & Do lar & 1 neto & 4 & Casada & Sogra \\
\hline $\mathrm{C} 4$ & 55 & $\begin{array}{c}\text { Ensino } \\
\text { fundamental } \\
\text { incompleto }\end{array}$ & Do lar & 4 netos & 2 & Divorciada & Mãe \\
\hline $\mathrm{C} 5$ & 68 & $\begin{array}{c}\text { Ensino } \\
\text { fundamental } \\
\text { incompleto }\end{array}$ & Do lar & 2 netos & 4 & Casada & Mãe \\
\hline C6 & 26 & $\begin{array}{l}\text { Ensino médio } \\
\text { Incompleto }\end{array}$ & Do lar & 4 sobrinhos & 1 & Solteira & $\begin{array}{c}\text { Irmã } \\
\text { Materna }\end{array}$ \\
\hline $\mathrm{C} 7$ & 33 & $\begin{array}{c}\text { Ensino } \\
\text { fundamental } \\
\text { incompleto }\end{array}$ & Do lar & 1 sobrinho & 3 & Casada & $\begin{array}{c}\text { Irmã } \\
\text { Materna }\end{array}$ \\
\hline
\end{tabular}

As participantes foram indicadas pelas detentas estudadas em pesquisa anterior. Elas disponibilizaram o número de telefone para que a pesquisadora pudesse convidar a pessoa responsável por seus(suas) filhos(as) a participar do presente estudo. A comunicação inicial com as participantes ocorreu por telefone, momento no qual foi explicitado o objetivo do estudo, seguido do convite. Dos 11 contatos indicados, sete concordaram em participar da pesquisa, uma não aceitou, um não se enquadrou nos critérios de inclusão por ser homem, marido da presa, e duas não foram localizadas.

Assim, mediante o aceite, foi agendada a entrevista, a qual foi norteada por questões sobre a rotina de cuidados com a criança/adolescente. Os encontros ocorreram todos nas residências das participantes e foram gravados em áudio e vídeo com duração média de 30 minutos cada um. Salienta-se que todas assinaram o Termo de Consentimento Livre e Esclarecido (TCLE) e, também, autorização para veiculação da imagempós a transcrição do áudio na íntegra, o texto foi submetido à análise de conteúdo proposta por Bardin (2011), a qual requer, em primeira etapa, uma leitura fluente que, constituída pelas falas iniciais, busca a identificação dos principais sentidos que as participantes atribuíram ao assunto investigado e qual o mais relevante diante da temática. Assim, na fase da exploração dos materiais, o conteúdo colhido foi listado e posteriormente agrupado conforme similaridade dos temas, resultando nas categorias finais. Ao término da análise, surgiram duas categorias que serão elucidadas e discutidas: Razões para cuidar e Relação familiar da cuidadora com a presa.

Para cumprir os critérios éticos desta pesquisa, foram atendidas as recomendações da Resolução $n^{\circ}$ 466/2012 do Conselho Nacional de Saúde que prescreve a ética em pesquisa com seres humanos (Brasil, 2012b). $\mathrm{O}$ projeto foi submetido e aprovado pelo Comitê de Ética em Pesquisa do Centro Universitário Franciscano, conforme parecer $\mathrm{n}^{\mathrm{o}} 2.392 .989$ de 2017. 


\section{Resultados e Discussão Categoria 1 - Razões para cuidar}

Das participantes deste estudo, as avós mostraram maior comprometimento nos cuidados, uma vez que o fato de criar os(as) netos(as) seja uma forma de preencher a falta do(a) filho(a) que estão ausentes pela detenção. O depoimento da C3 elucida esse sentimento:

"Mais sinto falta dele, bah! É, mais tá bem... Mais o guri é mesma coisa que seja um filho...é um filho. Mais que um filho, né?" (C3).

A pluralidade dos arranjos familiares atuais está muito distante dos padrões tradicionais de cuidados onde pai, mãe e filhos(as) consanguíneos convivem sob o mesmo teto. A tarefa de cuidar, proteger e educar os(as) filhos(as) torna-se cada dia mais complexa diante das novas concepções familiares estabelecidas na contemporaneidade (Cardoso \& Costa, 2012; Jaeger, Kruel \& Siqueira, 2011).

No que tange à realidade das mães presas e os cuidados aos seus(suas) filhos(as), perpassa uma configuração de papéis geracionais das mulheres, onde os menores passam a ser cuidados por outras pessoas, também mulheres, avós e tias que, na grande maioria, são a referência materna na vida dessas crianças. O que é ilustrado nas falas de duas avós participantes deste estudo:

Porque ele é filho do meu...meu filho né? Eu tenho pena de largá pelo mundo, a senhora não acha? ... Então eu cuidei por isso, eu cuido, por isso, porque ninguém qué, ninguém, ninguém, ninguém qué. Ninguém qué. (C1)

Quando eu peguei as crianças, ela não era presa, ela era...era drogada. Né? Daí eu assumí as criança porque ela não cuidava direito né. O guri, tinha seis mês daí a gente viu que não tava dando eu e o vô deles né e as tia, aí eu assumí...as criança. Aí criei, terminei de cria. (C5)

Os relatos acima vão ao encontro do descrito no estudo de Lopes (2015), no qual as mães presas suscitam que, após a prisão, seus(suas) filhos(as) foram encaminhados(as) aos cuidados de mulheres próximas, como mães, irmãs, tias ou até mesmo vizinhas. Raramente os homens assumem essa função sozinhos, pois tendem a constituir outra família, deixando os(as) filhos(as) para trás.

Como compreendido por Cardoso e Costa (2012), a família vem sofrendo constantes transformações socioculturais e históricas no que refere a sua configuração. E muitas condições surgem dessa realidade, onde as mulheres, em especial as avós costumam assumir o papel não só de auxiliares nos cuidados, mas o de mães substitutas. Para a participante $\mathrm{C} 4$, o exercício da maternidade, como função natural e de sucessão na vida da mulher, parece ficar bem evidente em seu relato:

Desde os três (3) meses (...) eu criei. Então meu filho diz não é da C. nada, é teu mãe. Mas no papel é dela. Eu nunca quis pegá a guarda. Agora mesmo queria que eu pegasse a guarda e eu fui e expliquei pra assistente social: pra que pegá a guarda se eu sô vó materna né?. (C4).

Embora a C4 crie o neto desde bebê, parece que há uma ambivalência no sentido de aceitar formal e definitivamente essa responsabilidade. Apesar da solicitação da Assistente Social, a avó prefere seguir cuidando sem um documento legal que ampare o papel desempenhado por ela na vida da criança.

Há inúmeras formas de desempenhar a parentalidade. A participante $\mathrm{C} 1$, que vivenciou momentos de ter duas de suas filhas presas, assumiu os cuidados dos(das) filhos(as) de ambas e, devido à sua condição social vulnerável e escassez de afeto em sua 
trajetória de vida, sua concepção de parentalidade é mais centralizada na manutenção diária das necessidades básicas do que na preocupação com a construção de valores e sustentação dos vínculos afetivos. Em sua fala, ela revela que:

Eu não conheci minha mãe, quando ela faleceu eu tinha um ano e pouco, fui criada com os padrasto, e meus padrasto eram ruim, eu dormia no chão na terra com as estopa, estopa pra dormi em cima e estopa pra se tapá. Ta, daí eu me puxava na roça desde os seis ano, aí eles me batiam demais que eu abichava eu andava, com bicheiras, tenho marca aqui na minhas costa e outra na cabeça que eu era abichada eu tomava muito laço eu me machucava muito na roça. (C1).

No relato da cuidadora $\mathrm{C} 1$, foi evidenciada a perda de referência parental desde tenra idade, com experiências de maus tratos e abandono emocional, o que corrobora com os estudos de Piccinini e Alvarenga (2012); Barroso e Machado (2010), ao descreverem que uma representação parental apropriada pode ser fundamental para $o$ estabelecimento de uma referência positiva na construção psicossocial do indivíduo. Para os autores, a consanguinidade não garante $\mathrm{o}$ empoderamento desse exercício, uma vez que se tornar pai ou mãe está fortemente ligado à história individual de cada um e de como essa representação foi internalizada pelo conceito de um modelo de família ideal.

A condição de cuidado provisório vivenciada pelas avós e tias desta pesquisa pode ser prejudicial às crianças e adolescentes que possuem suas mães presas. No momento em que elas evidenciam a não apropriação do lugar parental que representa a mãe, o que pode prejudicar o desenvolvimento psicoemocional da criança, sujeita a crescer à espera da mãe biológica, nunca se sentindo amada e protegida o suficiente por suas cuidadoras. Também pode repercutir de forma negativa na constituição subjetiva da criança, na medida em que fica pouco estabelecida ou ausente uma importante referência parental (Dias, Silva \& Barros, 2012). Essa condição se verifica no discurso de três cuidadoras desse estudo, C6, C4 e C1.

Eu vou passar as crianças pra ela, pra ela sê mãe das crianças e vou me afastar. Porque ela sabendo que eu to aqui, ela vai sempre fazê. Entendeu? Daí tem alguém que cuide dos filhos dela. Eu vo segui a minha vida e ela que cuide dos filhos dela. É isso que vai acontece. (C6)

Eu nunca quis pegá a guarda... mas ela me diz: mãe, vô perde tooodos meus filho pra ti, eu digo: Não vai não, quando tu saí eles vão voltá pra ti. Eu acho que vão com ela...se enxergá a mãe eles vão embora com ela. (C4)

Ainda bem que a mãe deles vem logo pra casa .... Ai sim vo vivê pra mim um pouco. $(\mathrm{C} 1)$

Nos relatos das cuidadoras percebe-se um desejo de que suas vidas retomem a rotina estabelecida antes da prisão de sua filha/ irmã, e de que as crianças voltem as suas mães após o cumprimento de suas penas. Isso, não necessariamente, irá ao encontro da realidade, pois o rompimento dos laços e vínculos entre mães e filhos(as) geralmente ocorreu por longo período de detenção. Dessa forma, distancia a relação mãe/filho(a) e elas podem tornar-se estranhas aos seus(suas) filhos(as) (Lopes, 2015). O que corrobora com o estudo de Flores (2018), no qual as mães presas apresentaram um desejo em reassumirem os cuidados e a convivência com os(as) filhos(as) após o cumprimento da pena. No entanto, sabem que não é fácil a estruturação de uma nova rotina, em razões do vínculo estabelecido com a cuidadora que assumiu as funções parentais.

Quando se fala em avós, remete-se imediatamente à ideia de fragilidade ou dificuldade associada à velhice, contudo, 
diante da longevidade e qualidade de vida dos idosos na contemporaneidade, esse parâmetro vem se modificando e tornando os avós referência parental para seus(suas) filhos(as) e netos(as) (Oliveira, 2011). Em contrapartida, muitas avós que assumem os cuidados efetivos dos(as) netos(as), sentem-se sobrecarregadas por não possuírem condições físicas, sociais e emocionais para tal responsabilidade (Mainetti \& Wanderbroocke, 2013).

Sobre as avós, este estudo mostrou que elas, de alguma forma, já auxiliavam nos cuidados com seus(suas) netos(as) antes mesmo de assumirem a criação deles(as). Mas que se encarregar dessa função não foi uma opção e sim uma necessidade. O exercício parental se sobrepôs ao papel de avó, diante da rotina diária, em que as funções vão muito além do vigiar e apoiar nos cuidados, exige o criar e o educar, funções até então destinadas aos genitores. Geralmente cabe a mulher a responsabilidade em assumir os cuidados e criação dos(as) filhos(as), podendo tornar-se difusas as funções de mãe e avó no decorrer do cotidiano (Deus \& Dias, 2016). No relato de C3, ela refere que sempre esteve próxima ao neto, mas que, com a prisão da nora e do filho concomitantemente, sentiu-se responsável em manter os cuidados de forma integral, desde a educação aos cuidados médicos.

A primeira vez que a mãe dele foi presa eu fiquei uns dia com ele, depois ela saiu, e voltou de novo. Mas ele quase sempre ficou com nós né? ... o problema que quando ela tá solta o guri passa doente, doente, doente, queria que vocês visse. Passo levando pro Pronto Atendimento $e$ pagando isso e aquilo e fazendo raio $x$ e sei o quê, tudo sempre. Digo não, isso aí por causa que ele não come comida de sal direito, só doçura, só doçura. Iogurte, bananinha, essas miojo né. (C3)

Nesta pesquisa, as participantes evidenciaram que, mesmo diante de condições financeiras desfavoráveis e da falta de apoio psicossocial, não cogitaram o abandono dos(as) netos(as) e sobrinhos(as). Todas referiram que diante da ausência da mãe biológica, sentiram-se responsáveis pelo criar como forma de não suscitarem novo abandono na vida das crianças. Como referido na fala da participante C6, tia materna e cuida de 4 sobrinhos. Ela relatou ter deixado para trás seus projetos de vida para assumir a criação dos menores.

Eu não morava aqui quando ela se prendeu, eu alugava uma casa. Daí a minha mãe faleceu e eu tive que vim pra cá cuidá deles, mas a mãe que cuidava, a mãe cuido sempre... A minha vida ta parada. Mas eu faço porque eu gosto, eu gosto deles. Entendeu? Não é nenhuma obrigação eu... gosto deles. Sô tia deles. Mas logo ela ta aí, daí ela retoma a vida dela e eu a minha. (C6)

Quanto às regras e limites imprescindíveis na educação, a cuidadora $\mathrm{C} 2$, avó materna, e C6, tia, também referiram certa dificuldade em exercê-la. Tanto o neto quanto o sobrinho, respectivamente, não as reconhecem como representantes parentais. Isso fica elucidado em seus relatos a seguir, e ratificado no estudo de Barroso e Machado (2010), em que parentalidade está relacionada ao controle da disciplina, com base na imposição de limites adequados a cada faixa etária, e como uma forma de controle comportamental e social da criança.

O guri é rebelde. O guri ele foge de casa as vez. Ele já foi parar até num abrigo de tão rebelde que ele é. Não é droga, não é álcool, não é... ele só se rebeldia comigo. Acho que ele pensa né? Não sô mãe dele, não sei...e se manda. Ele que se manda. Agora ele anda mais calmo. Mas isso aí tudo refletiu nele. (C6)

É complicado, porque eu a vida toda, criei o outro, o mais velho sem incomodação nenhuma e agora esse, começou com dez anos, com dez anos 
ele começo a apronta. (C2)

O impacto do aprisionamento de uma mãe sobre os(as) filhos afeta todos os aspectos de suas vidas e não apenas no relacionamento entre eles. Para a criança, a separação e o afastamento repentino da mãe pela prisão é semelhante ao luto e, se não bem elaborados, podem levá-los ao desenvolvimento de um comportamento agressivo ou antissocial no futuro (Taylor, 2004).

\section{Categoria 2 - Relação familiar da cuidadora com a presa}

A vivência do abandono familiar foi constatada durante a coleta de dados desta pesquisa. Foram feitas várias tentativas de encontro com as responsáveis por essas crianças/adolescentes em dias de visita ao presídio. Mesmo em datas especiais como dia das mães, o número de visitantes era muito pequeno e as poucas pessoas encontradas no local não atendiam aos critérios de inclusão deste estudo. Esta realidade é descrita em alguns estudos sobre o aprisionamento feminino (Flores, 2018; Medeiros, 2010; Santos, Néri, Oliveira, Quitete, \& Sabroza, 2009; Taylor, 2004), apontando que a razão para a ausência de visitantes é multifatorial: dificuldades financeiras, difícil acesso até os presídios, constrangimentos em revistas íntimas, relações familiares conflituosas, entre outros. Esses são alguns dos vários impedimentos para a manutenção da convivência. Isso também é explicitado na fala das participantes C5 e C2, que referem o ressentimento com a filha pelo comportamento transgressor.

Não eu não, eu não visito, não visito mesmo. Ela chora... pode chora, mas não vou. (C2)

Não vou porque eu...eu vou tá me matando em fila de presídio e sendo humilhada, porque a gente é humilhada nessas revista. Eu disse que não vou...não vou mais. (C5)

A participação da família durante o período de reclusão ameniza o sofrimento e mantém os laços afetivos existentes antes da prisão. Isso contribui para a socialização e o suporte emocional, podendo assim diminuir as chances de reincidência, pois, com a perda do vínculo familiar e de um objetivo futuro, aumenta a probabilidade de retorno ao mundo do crime (Medeiros, 2010). Entretanto, o que acontece na maioria dos casos estudados nessa pesquisa é o enfraquecimento dos laços afetivos, entre outros aspectos, pela dificuldade do cuidador em levar as crianças até as mães, por falta de recursos financeiros e sociais. O que pode ser evidenciado pelas cuidadoras $\mathrm{C} 3$ e $\mathrm{C} 6$, respectivamente.

Daí eu quase não vô lá por causa que como é que eu vou deixá as criança cum os ostros né?! (C3)

Não, não tem como, é muito puxado pra mim, não tem como eu ta levando todo mundo pra lá,...não tem como. Eu não tenho tempo, ... tem uns que estudam de manhã, outros de tarde eu nunca tô com todos eles junto. (C6)

Frente a essas premissas e com base no relatado pela maioria das pesquisadas que são mães de mães presas, percebe-se que, mesmo velado, paira um sentimento de culpa pelo comportamento transgressor de suas filhas, entretanto, esse sentimento também é sentido pelas filhas que se sentem responsáveis pelos sofrimentos de ordem psicoemocional de suas mães. O que se evidencia no estudo de Matos e Machado (2007) é que as mulheres presas se sentem preocupadas e culpadas pelo sofrimento emocional e físico vivenciados por seus familiares, levando-as a crer que, antes de suas detenções, seu contexto familiar fosse isento de qualquer tipo de problemas e os mesmos só teriam se iniciado após suas prisões. Nesse estudo, as participantes C1, C4 e C5 narraram esse sentimento.

Eu trabalho em qualquer casa não tem problema... os filho que não souberam vive não souberam me trata bem... o que uma mãe passa pra 
tê um filho, de depois viram uns drogado $(C 1)$.

Ela teve bem, bem envolvida nas droga, aí ela foi presa. Daí ela começo a fazê arte no centro né? Ela andava por aí né? Foi ...se misturando e...né? Que eu acho que alguém, (risos) eu acho na minha opinião que ninguém obriga ninguém a fazer nada né? Só faz se qué. (C5)

A X foi uma guria assim ó, até os dezoito era uma beleza de filha. Fez dezoito caiu nas droga. Dois anus eu corri atrás dela, invadia, deixava meu filho, ele era de menor na época né? Sozinho (...) Foi, foi, foi, foi que largou das droga. Aí engravidou do P.... Essa cadeia nã̃ãa é deeeela. (C4)

C4 crê que sua filha foi presa injustamente, quando refere em seu discurso que a "prisão não é dela". Inúmeras vezes a mulher presa possui dificuldades em manter diálogo e relação harmoniosa com os cuidadores de seus(suas) filhos(as), o que repercute negativamente na manutenção e construção de um vínculo saudável com os menores (Granja, Cunha \& Machado, 2013; Jesus, Oliveira, Oliveira, Brandão, \& Costa, 2015). Este estudo constatou que a falta de convivência das mães presas com suas filhas é prejudicial à manutenção e ao estabelecimento dos vínculos afetivos. Vínculos já fragilizados não só por questões burocráticas do presídio e dificuldades financeiras, mas em decorrência de sentimentos antagônicos como raiva, culpa, pena e desejo de punir a mãe transgressora. Como visualizado no relato da cuidadora C6 que assumiu os(as) quatro sobrinhos(as) e não possui nenhum apoio das outras irmãs, pois as mesmas não perdoaram o comportamento reincidente da primogênita.

Ela é reincidenti, $i$ foi avisada a não lidar mais com isso, $i$ ela né...? Se envolveu de novu $i$ minhas irmãs $s i$ encheram do saco, $i$ não quiseram sabê nem das criança. (C6)
De acordo com a Resolução do Conselho Nacional de Política Criminal e Penitenciária- CNPCP $\mathrm{n}^{\mathrm{o}} 3$, art. $8^{\circ}$ de julho de 2009, a visita de familiares e pais presos deve ser estimulada visando à preservação do vínculo familiar e do reconhecimento de outros personagens do círculo de relacionamento parental (Brasil, 2009). O que de certa forma já era previsto pelo Relatório das Mulheres Encarceradas no Brasil em 2007, quando se discute a manutenção das relações familiares, vê-se que a violência praticada contra a mulher presa ultrapassa os limites da pena, atingindo também a sua família e, especialmente, os(as) filhos(as) (Brasil, 2007). $\mathrm{O}$ que fica evidenciado nesse estudo corroborando com os aspectos negativos mais incidentes nas vidas das mulheres presas que é o distanciamento da família, diferentemente da realidade vivenciada pelos homens presos, os quais em geral mantém seus vínculos familiares durante $\mathrm{o}$ período de encarceramento.

Deve-se questionar sobre a possibilidade e disponibilidade de serviços à mulher presa, que contribuísse na manutenção dos vínculos familiares e facilitasse o convívio familiar e social, a fim de reverem seus amigos para que pudessem reconquistar uma oportunidade no mercado de trabalho quando egressas. A maioria delas passa por um longo período longe da família, dos amigos e da comunidade (Dias et al., 2012), o que pode dificultar sua reinserção social.

\section{Considerações finais}

$\mathrm{Na}$ realidade das mães presas, há a necessidade da transferência da responsabilidade dos cuidados para outras pessoas, muitas vezes, avós e tias. Neste estudo, constatou-se que a responsabilidade foi assumida na contramão do desejo e por necessidade extrema. Ainda que as avós tenham baixa renda, pouca escolaridade e idade avançada, elas aceitaram a missão de substituir a mãe biológica.

Em relação às avós, as dificuldades parecem ser enfrentadas com resignação, 
talvez uma forma de reparar aspectos que pensam ter falhado durante o desenvolvimento das próprias filhas, hoje adultas que entraram em conflito com a lei. Assim, elas assumem integralmente as funções parentais, enquanto esperam por um futuro incerto. Será que suas filhas conseguirão retomar a função parental? Isso elas não sabem, mas com certeza, gostariam de acreditar em um futuro mais próspero.

Embora elas já participassem dos cuidados dos(as) netos(as), assumir a criação de forma integral não foi uma opção e sim uma necessidade. O papel de mãe se sobrepõe ao papel de avó, visto a necessidade de dar conta de uma tarefa na qual os filhos estão impedidos.

Para todas as participantes deste estudo, manter a convivência com seu familiar e auxiliar na manutenção dos vínculos entre mãe e filho(a) é uma tarefa praticamente impossível, visto que as participantes provêm de famílias carentes, residentes em zonas periféricas distantes do presídio, o que dificulta muito o deslocamento, mesmo que esporádico, até a instituição prisional. Soma-se a isso a ausência de motivação para visitar a presa, a qual pode ser compreendida pelo desgosto, ressentimento e mágoa por terem se envolvido em situações ilícitas, assim como pela sensação de constrangimento pela revista íntima.

Conclui-se, sinalizando a importância de novos estudos sobre a repercussão familiar diante da prisão feminina, inclusive a partir do olhar dos(as) próprios(as) filhos(as) das detentas. É necessário ampliar a rede de apoio da cuidadora e buscar minimizar o dano da falta de convivência, evitando o abandono da mulher presa. $\mathrm{O}$ investimento na manutenção dos vínculos é ferramenta para que, após o cumprimento da pena, exista a possibilidade de reestabelecer a família na sua constituição original.

\section{Referências}

Bardin, L. (2011). Análise de conteúdo (4 ${ }^{\mathrm{a}}$ ed.). Lisboa: Edições 70.

Barroso, R. G., \& Machado, C. (2010). Definições, dimensões e determinantes da parentalidade. Psychologica, 1, 211-229.

Brasil. (1990). Lei n. 12.962, de 08 de abril de 2014: altera a Lei $n^{\circ} 8.069$, de 13 de julho de 1990 (Estatuto da Criança e do Adolescente). Recuperado de https://legis.senado.leg.br/sdleggetter/documento?dm=7635794\&dispositio $\underline{\mathrm{n}=\text { inline }}$

Brasil. Centro pela Justiça e pelo Direito Internacional. (2007). Relatório sobre mulheres encarceradas no Brasil. São Paulo: Instituto Brasileiro de Ciências Criminais. Recuperado de http://carceraria.org.br/wpcontent/uploads/2013/02/Relato\%CC\%81ri o-para-OEA-sobre-Mulheres-Encarceradasno-Brasil-2007.pdf

Brasil. Conselho Nacional de Justiça. (2012a). Cartilha da nulher Presa (2 ed.). Brasília, DF: CNJ.
Brasil. Conselho Nacional de Justiça. (2017). Levantamento Nacional de Informações Penitenciárias: INFOPEN Mulheres. Brasília, DF: CNJ. Recuperado de https://www.justica.gov.br/news/estudotraca-perfil-da-populacao-penitenciariafeminina-no-brasil/relatorio-infopenmulheres.pdf

Brasil. Ministério da Justiça. Conselho Nacional de Política Criminal e Penitenciária. (2009). Resolução CNPCP $n^{\circ} 3$, de 15 de julho de 2009: disciplina situação de filhos de mulheres encarceradas. Brasília: Ministério da Justiça/ CNPCP. Recuperado de https://www.ibccrim.org.br/noticia/13345Resolucao-do-CNPCP-disciplina-situacaode-filhos-de-mulheres-encarceradas

Brasil. Ministério da Saúde. (2012b). Resolução n. 466/CNS, de 12 de dezembro de 2012: diretrizes e normas regulamentadoras de pesquisas envolvendo seres humanos. Brasília, DF: Ministério da Saúde. Recuperado de 
http://bvsms.saude.gov.br/bvs/saudelegis/cn s/2013/res0466_12_12_2012.html

Cardoso, A. R., \& Brito, L. M. T. (2014). Ser avó na família contemporânea: Que jeito é esse?. Psico-USF, 19(3), 433-441. doi: 10.1590/1413-82712014019003006

Cardoso, V. S., \& Costa, L. F. (2012). Família e justiça: guarda judicial de netos e o ciclo de vida do idoso. Pensando Famílias, 16(2), 137-151. Recuperado de http://www.domusterapia.com.br/site/princi $\mathrm{pal} /$ revista_nivel3.asp?codConteudo $=441$

Deus, M. D., \& Dias, A. C. G. (2016). Avós cuidadores e suas funções: uma revisão integrativa da literatura. Pensando Famílias, 20(1), 112-125. Recuperado de http://pepsic.bvsalud.org/scielo.php?script= sci_arttext\&pid=S1679494X2016000100009\&lng=pt\&tlng=pt

Dias, P. E., Silva, G. G. F., \& Barros, D. M.V. (2012). A reconstrução dos vínculos afetivos, familiares e comunitários de uma egressa do presídio feminino do distrito federal. Revista Projeção, Direito e Sociedade, 3(1), 228-251. Recuperado de http://revista.faculdadeprojecao.edu.br/inde X.php/Projecao2/article/view/164

Diuana, V., Ventura, M., Simas, L., Larouzé, B., \& Correa, M. (2016). Direitos reprodutivos das mulheres no sistema penitenciário: tensões e desafios na transformação da realidade. Ciência \& Saúde Coletiva, 21(7), 2041-2050. doi: $\underline{10.1590 / 1413-81232015217.21632015}$

Figueiredo, B. \& Lamela, D. (2014). Parenting and coparenting: basic concepts and intervention programs (Contributos para a intervenção em Psicologia). Porto: Universidade Católica Portuguesa.

Flores, N. M. P. (2018). Um abraço sem grades: documentário sobre a maternidade no sistema prisional (Dissertação de Mestrado Profissional). Universidade Franciscana, Santa Maria.

Granja, R., Cunha, M. P., \& Machado, H. (2013). Formas alternativas do exercício da parentalidade: paternidade e maternidade em contexto prisional. Ex aequo, (28), p.7396. Recuperado de http://www.scielo.mec.pt/scielo.php?script
$=$ sci_arttext\&pid $=$ S087455602013000200007\&lng $=p t \& t \operatorname{lng}=p t$ Jaeger, F.P., Kruel, C.S., \& Siqueira, A.C. (2011). Parentalidade e contemporaneidade: os desafios para a psicologia. Santa Maria: UFN.

Jesus, A. C. F., Oliveira, L. V., Oliveira, E, A., Brandão, G. S. G., Costa, G. M. C. (2015). $\mathrm{O}$ significado e a vivência do abandono familiar para presidiárias. Ciência \& Saúde, 8(1), 19-25. doi: $10.15448 / 1983-$ 652X.2015.1.19535

Lopes, K. M. (2015). Noções sobre responsabilidades femininas e o cuidado familiar em um grupo de mulheres encarceradas. Clinica \& Cultura, 4(1), 7178. Recuperado de: https://seer.ufs.br/index.php/clinicaecultura/ article/view/4071

Mainetti, A. C., \& Wanderbroocke, A. C. N. S. (2013). Avós que assumem a criação dos netos. Pensando Família, 17(1), 87-98.

Recuperado de http://pepsic.bvsalud.org/scielo.php?script= sci_arttext\&pid=S1679494X2013000100009\&lng=pt\&tlng=pt

Matos, R., \& Machado, C. (2007). Reclusão e laços sociais: discursos no feminino. Análise Social, 42(185), 1041-1054.

Recuperado de http://www.scielo.mec.pt/scielo.php?script =sci_arttext\&pid=S0003$25732007000400005 \& \ln \mathrm{g}=\mathrm{pt} \& \operatorname{lng}=\mathrm{pt}$

Medeiros, L. L. (2010). Mulheres e cárcere: reflexões em torno das redes de proteção social. Anais do X Encontro Nacional de História Oral, Recife, PE, Brasil, 10.

Recuperado de

http://www.sul2013.historiaoral.org.br/reso urces/anais/2/1269096793_ARQUIVO_Tra balhocompletomulheresecarcere.pdf

Oliveira, M. R. (2011). As relações intergeracionais e a participação dos avós na família dos filhos (Tese de Doutorado). Universidade de Brasília, Brasília.

Piccinini, C. A., \& Alvarenga, P. (2012).

Maternidade e paternidade: $a$ parentalidade em diferentes contextos. São Paulo: Casa do Psicólogo.

Santos, M. B. S., Néri, H. F., Oliveira, M. F. 
L., Quitete, B., \& Sabroza, A. (2009). Do outro lado dos muros: a criminalidade feminina. Mnemosine, 5(2), 174-188.

Recuperado de

http://www.mnemosine.com.br/ojs/index.p $\mathrm{hp} / \mathrm{mnemosine} /$ article/view/180
Taylor, R. (2004). Women in prison and children of imprisoned mothers. Geneva: Friends world committee for consultation (Quakers). Recuperado de http://www.crin.org/en/docs/resources/treat ies/crc.40/GDD_2005_Quakers_I.pdf

\section{Dados sobre as autoras:}

- Liziane Falleiro dos Santos Arruda: Graduada em Psicologia pela Universidade Luterana do Brasil -ULBRA Cachoeira do Sul (2008). Especialista em Docência para curso profissional pelo SENAC (2010). Mestre em Saúde Maternoinfantil pela Universidade Franciscana -UFN (2019). Docente na Escola Técnica Albert Einstein- SEG Santa Maria. Qualificada em TCC pela WP Psicologia. Perita psicóloga nas varas da Família no Fórum de Santa Maria Tribunal de Justiça do Estado do Rio Grande do Sul.

- Luciane Najar Smeha: Possui gradação em Psicologia pela Universidade do Vale dos Sinos (1994) e mestrado em Psicologia Social pela Pontifícia Universidade Católica do Rio Grande do Sul (2006) e doutorado em Psicologia pela Pontifícia Universidade Católica do Rio Grande do Sul (2010). Atualmente é professora adjunta na Universidade Franciscana -UFN, docente nos cursos de especialização em Psicologia Clínica, Psicopedagogia e Família na Contemporaneidade. Tem experiência em intervenção e pesquisa na área de Psicologia com ênfase nos seguintes temas: Dinâmica familiar na perspectiva sistêmica, fases evolutivas da família, conjugalidade, parentalidade, relação mãe/bebe, relações familiares no contexto da criança com deficiência, deficiência intelectual, síndrome de Down, autismo, paralisia cerebral e inclusão escolar. Desde 2015 membro do corpo docente e do colegiado do curso de Mestrado Profissional em Saúde MaternoInfantil. 